\title{
THE COMPLEX INVESTIGATION OF THE COLONIZATION POTENTIAL OF AEDES ALBOPICTUS (DIPTERA: CULICIDAE) IN THE SOUTH PANNONIAN ECOREGION
}

\author{
TRÁJer, A. ${ }^{*}{ }^{*}$ - TÁNCZOS, B. ${ }^{2}$ - HAMMER, T. ${ }^{3}$ - BEDE-FAZEKAS, Á. ${ }^{4,5}$ - RANVIG, K.-A. ${ }^{6}-$ \\ SCHOFFHAUZER, J. ${ }^{6}-$ PADISÁK, J. ${ }^{1,3}$ \\ ${ }^{1}$ MTA-PE Limnoecology Research Group, H-8200, Veszprém, Egyetem utca 10. \\ ${ }^{2}$ Hungarian Institution for Forensic Sciences, Department of Genetics, \\ H-1087 Budapest, Mosonyi u. 9. \\ (phone/fax: +36-1-477-2161; e-mail: tanczosb@gmail.com) \\ ${ }^{3}$ University of Pannonia, Department of Limnology; H-8200, Veszprém, Egyetemutca 10. \\ (phone: +36-88-624-747; e-mail: hammer.t88@gmail.com) \\ ${ }^{4}$ MTA Hungarian Academy of Sciences, Centre for Ecology, Institute of Ecology and Botany, \\ H-2163 Vácrátót, Alkomány u. 2-4. \\ (phone: +36-28-360-122/133) \\ ${ }^{5}$ Szent István University, Faculty of Landscape Architecture and Urbanism, Department of \\ Garden and Open Space Design, H-1118, Budapest, Villányi út 29-43. \\ (phone: +36-1-482-6308) \\ ${ }^{6}$ Independent authors \\ *Corresponding author \\ e-mail:atrajer@gmail.com; \\ (phone/fax:+36-88-62-4747; mobile: +36-20-330-9186) \\ (Received $2^{\text {nd }}$ Aug 2016; accepted $26^{\text {th }}$ Nov 2016)
}

\begin{abstract}
Aedes albopictus is the potential vector of several pathogens. Recently, the South Pannonian ecoregion has been the border of the east Mediterranean established range of the species. We aimed to determine the current range limiting factors, to predict the potential seasonality and to model the future distribution of the mosquito in the Carpathian Basin. Mosquito trapping was performed in the border region. Larvae were collected from local waters. Based on the new and the previously performed collections, we analysed the limiting climatic factors of the occurrence. The calculation of the full ontogeny was based on previously published experimental results. The analysis of the climate of the successful and non-successful trapping sites showed the complex conditionality of the habitat preference of Aedes albopictus. We confirmed the presence of Phlebotomus neglectus in South-western Hungary and of Aedes albopictus in Zagreb. We found that Aedes albopictus can tolerate the climate of the mountainous regions of the Mediterranean where there are relatively cold winters due to high annual precipitation. Both the climate envelope model results and the gained range limiting factors support the hypothesis that the recent climate of Hungary allows the expansion of the mosquito in the Carpathian Basin.
\end{abstract}

Keywords: climate envelope modeling, established occurrence, Köppen-Geiger climate classification, potential generation number, mosquito trapping, Phlebotomus neglectus

\section{Introduction}

Aedes (Ae.) (Stegomyia) albopictus Skuse (1894), also known as the Asian tiger mosquito is a competent vector for at least 22 arboviruses including Dengue virus, 
Chikungunya virus, Zika-virus, West Nile virus, St. Louis encephalitis and Japanese encephalitis (Bonialuri et al., 2008; Grard et al., 2007; Gratz 2004; Ibáñez-Bernal et al., 1997; Knudsen et al., 1996; Moore and Mitchell, 1997; Sardelis et al., 2002; Wong et al., 2013) as well as several species of filarial nematodes e.g. Dirofilaria species (Hochedez et al., 2006; Cancrini et al., 2003). The rapid spread of Ae. albopictus and the transmitted pathogens were observed in the last few decades (Knudsen et al., 1996; Mitchell, 1995; Urbanelli et al., 2000). Since the first European appearance in Albania, the Asian tiger mosquito demonstrated a remarkable invasive potential in the Mediterranean region (Urbanelli et al., 2000). The mosquito recently occurs in each of the countries from Portugal to Greece (Benedict et al., 2007; Kalan et al., 2011; Klobučar et al., 2006; Merdić, 2011; Petrić et al., 2001, 2006; Scholte and Schaffner, 2007). Due to Yugoslav war and the political redistributions of the past few decades in the Balkan there are relatively sparse data about the climatic limitations of Ae. albopictus populations in the South Pannonian ecoregion and the Northern Balkan which is the doorstep of the Central European region. What is an alarming phenomenon for Central Europe that introduced occurrences of the mosquito were observed in Slovakia and the Czech Republic more recently (Bocková et al., 2013; Šebesta et al., 2012).

Ae. albopictus is abundant in such areas where the mean annual temperature is more than $11^{\circ} \mathrm{C}$ (the threshold of adult activity and survival), mean winter temperature more than $0^{\circ} \mathrm{C}$ (the threshold of egg overwintering) and the mean annual precipitation is at least $500 \mathrm{~mm}$ (Medlock et al., 2006; Mitchell, 1995). For comparison, the mean annual temperature is $10-11^{\circ} \mathrm{C}$, the annual precipitation is $500-750 \mathrm{~mm}$ and the mean January temperature is between -0.3 and $-2{ }^{\circ} \mathrm{C}$ in most of the areas of Hungary according to the 1971-2000 reference period (OMSZ). It was pointed out that Ae. albopictus may not survive through winter if the diapause period exceeds six months (Medlock, 2006). It means that in certain parts of Hungary, the climatic threshold already approximates the climatic requirements of Ae. albopictus in the last three decades of the $20^{\text {th }}$ century. Based on the recent dispersal rate and climate suitability of the species, the predicted effects of climate change, the future spread of the mosquito into the recent temperate climate areas of Europe is very likely (Knudsen et al., 1996; Mitchell, 1995). Ae. albopictus prefers the peridomestic environment, breeding in both natural and artificial small waters colonizing even barrels, drinking troughs, rainwater gulley catch basins, tires and several other type of technotelmata (Gatt et al., 2009). According to their breeding habitat preference, the Asian tiger mosquito can inhabit the urban and suburban habitats (Juliano and Lounibos, 2005). The length of the activity and the reproductive season and egg diapause is controlled predominantly by the ambient temperature conditions. The photoperiodic threshold of the production of diapausing eggs occurs below 13 or 14 hours of daylight in many locations; however in some northern areas it can occurs at 11 or 12 hours (Medlock, 2006). Air temperature has also important influence on the population dynamics (Alto and Juliano, 2001) and the ontogeny of Ae. albopictus (Delatte et al., 2009; Calado and Silva, 2002). Higher temperature conditions increase the speed of the development, the number size and the rates of the winter survive of diapausing eggs (Medlock et al., 2006). The minimal threshold of each ontogenic stage is at $10.4^{\circ} \mathrm{C}$, the optimum is at $29.7^{\circ} \mathrm{C}$ based on the experimental investigations of Delatte et al. (2009). The populations of the Asian tiger mosquito living in the tropical and subtropical areas have no winter diapause. Under cooler climatic conditions, the populations of Ae. albopictus can overwinter by producing eggs which have winter diapause (Medlock et al., 2006). The production of 
overwintering eggs is triggered by the decreasing tendency of daylight hours and occurs in late summer and early autumn.

The adaptation of Ae. albopictus to the cooler European conditions were observed due to the increasing hatching success and cold tolerance of diapausing eggs of the European Ae. albopictus populations (Thomas et al., 2012). In addition, in the Mediterranean, as the coastal and lowland areas of the Apennine Peninsula where the more severe freeze is rarely occur, the populations of the Asian tiger mosquito shows the signs of cold-acclimation as adults and remain active throughout the entire winter season (Romi et al., 2006). Larval development including each of the instars takes 3-8 weeks, while the mean lifespan of the adults is about 3 weeks, although in case of the overwintering individuals of female mosquitoes in the Mediterranean area it can takes some months (Gatt et al., 2009). The length of activity varies according to the annual temperature patterns and the peak season also changes according to the availability of blood meal and water in a certain area. Giatropoulos et al. (2012) found that the numbers of the produced eggs are the highest in mid-July to November.

Romi et al. (2006) proved that Ae. albopictus can adapt for the local environment which means that natural selection results strains with different climatic requirements and overwintering potential. According to this fact, the special investigation of the environment requirements of the North Balkan climatic strains is justifiable. While the potential future established range of the species falls within the Carpathian Basin, it remained a somewhat under-represented area in the more recent distribution modeling studies. We studied the range-limiting climatic factors of Ae. albopictus supplementing the previously published occurrence data with the result of our collecting survey in the transition of the south part of the Pannonian ecoregion and the North Balkan. We focused on the established occurrences of the species. Our aim was also to model the potential near future distribution and generation numbers of the Asian tiger mosquito according to the temperature patterns of the last 10 years.

\section{Materials and Methods}

\section{The three employed approaches}

The course of the study was the following: according to the results of our survey and completed with the data and results of other trapping surveys (respecting the mapped data of the European Centre for Disease Control and Prevention's V-BORNET program, 2015) we aimed to analyze the climatic factors of the distribution in the studied area and to correlate the found suitable and non-suitable climatic conditions with the climate categories of the Köppen-Geiger climate classification system. In this study, the analysis of the climatic factors of the present occurrence of Ae. albopictus also was based on the established habitats of the mosquito in the studied area. Occurrences based on a single observation were not taken into consideration since only one milder can lead to the survival of the species in a given site.

The near future spread of the Asian tiger mosquito was studied along three main ideas:

1) the analysis of the limiting factors of the current distribution that may reflect rather the climate patterns of the near past than the present conditions,

2) the calculation of the potential annual generation numbers which approach also show the climatic suitability of the mosquito in a given area

3 ) and the prediction of the recent and the near future potential distribution of the mosquito using a climate envelope model. 


\section{Climate data sources}

The climatic database of the Climate Explorer of the European Climate Assessment and Data was used at the Climate Explorer homepage of the Koninklijk Nederland Meteorologisch Institut (KNMI, 2014). The half-gridded climate data of the E-OBS climate model was used with $0.25^{\circ}$ resolution. Mean minimum January temperature $\left({ }^{\circ} \mathrm{C}\right)$, January mean temperature $\left({ }^{\circ} \mathrm{C}\right)$, sum of the autumn and winter precipitation $(\mathrm{mm})$ and mean July precipitation (mm) were invoked for the period of 1950-2014. Since Ae. albopictus appeared in Croatia and Slovenia in the 2000's, the most recent climatic data from the $1^{\text {st }}$ of January 2000 to the $1^{\text {st }}$ of October 2014 were used and the data was averaged for this period in each of the 49 involved trapping sites. The 49 sites represent 20 control non-successful and 29 successful trapping sites which consist of 16 sites from our own collector survey representing the surveyed area in climatic aspect ( 7 sites from Hungary, 7 from Croatia and 2 from Slovenia). For the calculation of the potential generation number in Hungary, the daily temperature values of the last ten years were averaged according to the following covering grid: $45.75-48.0 \mathrm{~N}$ and $16.0-23.0 \mathrm{E}$.

For modeling the recent and future distributions of Ae. albopictus, we used the REMO climate model, which is nested into the ECHAM5 global climate model and is based on the IPCC SRES A1B scenario. 1961-1990 is the reference period and the periods of 2011-2040 and 2041-2070 are the selected prediction periods. REMO has 25 $\mathrm{km}$ horizontal resolution and the entire Europe is within its domain. The A1 scenario family describes an economically rapidly developing world with a similar rapid technological evolution and unimodal global population run with a peak in the mid-21th century (IPCC reports; Working Group I: The Scientific Basis). The A1 is based on the idea of the increasing volume of the socio-cultural and innovative interactions what is a clear trend in the age of the recent electronic social network revolution and in the light of the volume of the multinational cooperation. The decrease of the regional differences is also an important basic idea of the A1 which trend recently is visible in the relation of the decreasing difference between the economy of the Western and the BRICs countries (Jain, 2006). Since the model studied the climate requirements only of the European populations - the North African distribution segments were excluded -, it was able to project the shift of this part only.

\section{Mosquito field survey}

The study area covers selected parts of four major river valleys, which fall in this area: the valley of Sava, Drava, Tisza (at Szeged city, Southeastern Hungary) and the Danube (at the Mohács town, South Hungary). Most of the mapping points were performed on the settlements which are adjacent to the floodplain of the Sava and Drava rivers. Drava is a river at the Hungarian-Croatian and Slovenian border, which was preserved in its natural conditions with oxbows, branches and a meandering mainstream with islands. We considered these areas optimal for natural expansion of Ae. albopictus, because river valleys are often regarded as natural conveyance routes in the temperate climate zone. Fig. 1 shows the sampling points.

Two CDC Miniature Light Traps (John W. Hock Company, Florida State, USA) were operated at five sites in or near to three villages in Hungary and in a recreational part of Zagreb, Croatia. Light traps were not baited with attractants such as carbon dioxide. Twenty eight, mostly small scale water bodies were sampled, 24 of which contained mosquito larvae. The larvae were collected with a fine scale sieve and 
reloaded into the filtered water of the respective sampled water body in individual twoliter open PET containers with openings covered by nets. About 10 to 20 dips with a fine scale sieve were taken per aquatic systems and 1-3 aquatic systems were sampled at each site. The containers were incubated at room temperature $\left(20-25^{\circ} \mathrm{C}\right)$ and protected from direct sunlight for 2 weeks. Later emerged adults were released to PVC bags and immediately killed by dry cold shock $\left(-20{ }^{\circ} \mathrm{C}\right)$ lasting for one hour, which left characteristic morphological features intact.

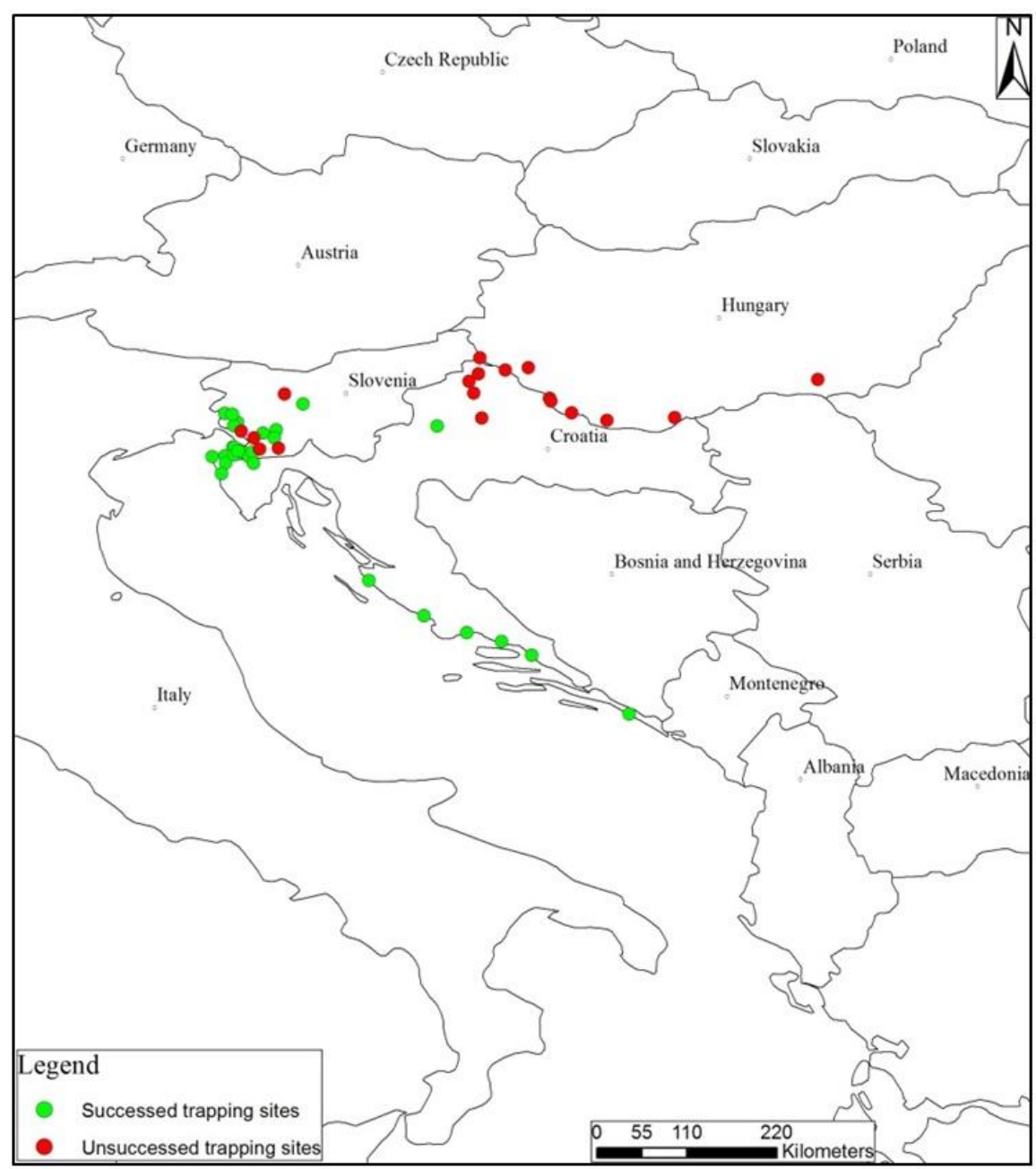

Figure 1. The sites of the trapping points used in the climatic analyses. Our trapping points were completed with the established (green) and non-established (red) occurrences of Ae. albopictus according to the trapping monitoring of Kalan et al. (2011) and Merdić et al. (2011).

\section{Additional trapping data}

In total, 49 trapping sites were added to the analysis, of which 8, 22 and 19 represented Southern Hungary, Slovenia and Croatia, respectively. The latter two sets of tiger mosquito trapping sites (Slovenia: Kalan et al., 2011; Croatia: Merdić et al., 2011) were introduced into our model to gain a wider climatic context. Positive and negative trapping points from every sub-region in the three studied countries were selected. In case of some Croatian data the $25^{\circ}$ grid of the trapping point were identifiable after the 
published maps, although the exact settlements are not in some north coastal area. In this cases a reference settlement were indicated in the subtitles of the figures. It is important to note that this circumstance does not affect the results of the study since only the climatic factors were used in the analyses, which are the same in a given $25^{\circ}$ grid according to the averaged values. For CEM, the distribution data of the mosquito was gained from the VBORNET database (VBORNET, 2015). Only the established occurrences of the mosquito were involved to the model.

\section{The calculations of the development times}

To create the temperature based development by ontogeny stages model of Ae. albopictus mosquito we used the observations of Calado and Silva (2002) who examined the development of the Asian tiger mosquito in each ontogeny stages under permanent temperature regimes $\left(15^{\circ} \mathrm{C}, 20^{\circ} \mathrm{C}, 25^{\circ} \mathrm{C}\right.$ and $\left.30^{\circ} \mathrm{C}\right)$. Since the minimal threshold temperature of the development of Ae. albopictus is $10.4^{\circ} \mathrm{C}$ (Delatte et al., 2009), under this threshold the development was not interpreted. We fit exponential regression model to the mean monthly temperature-period of development pairs of the data of Calado and Silva (2002) to gain correlations between temperature and the mean time of the steps of the metamorphosis according to the minimum time of the ovuleinstar $1^{\circ}$ metamorphosis (Eq.1,), the minimum cumulative time of the instar $1^{\circ}$ to the instar $4^{\circ}$ metamorphosis (Eq.2) and the mean time of the pupa-adult metamorphosis (Eq.3) under different temperature conditions. The basic equations can be seen in the Fig.6 according to the experimental results of Calado and Silva (2002):

$$
\begin{aligned}
& \mathrm{t}_{\mathrm{ov}-1^{\mathrm{s}}}=82.171 \mathrm{e}^{-0.101 \mathrm{~T}} \text { if } 30^{\circ} \mathrm{C} \geq \mathrm{T} \geq 10.4^{\circ} \mathrm{C} \\
& \mathrm{t}_{1^{\mathrm{s}-4^{\circ}}}=155.57 \mathrm{e}^{-0.114 \mathrm{~T}^{\circ}} \text { if } 30^{\circ} \mathrm{C} \geq \mathrm{T} \geq 10.4^{\circ} \mathrm{C} \\
& \mathrm{t}_{\mathrm{p}-\mathrm{a}}=34.051 \mathrm{e}^{-0.098 \mathrm{~T}} \text { if } 30^{\circ} \mathrm{C} \geq \mathrm{T} \geq 10.4^{\circ} \mathrm{C}
\end{aligned}
$$

where $\mathrm{T}$ is the daily mean temperature in ${ }^{\circ} \mathrm{C}$, tov- $1^{\circ}$ is the minimum cumulative time of the ovule-instar $1^{\circ}$ metamorphosis, $\mathrm{t} 1^{\circ}-4^{\circ}$ is the minimum cumulative time of the instar $1^{\circ}$ to the instar $4^{\circ}$ metamorphosis and tp-a is the time of hatching (Fig.2).

The total (minimum) development time an individual is the sum of the (minimum) time of the each ontogeny times (Eq.4):

$$
t_{\text {total }}=t_{o v-1^{s}}+t_{1^{s}-4^{s}}+t_{p-a}
$$

An ontogeny stage is completed, when the sums of the daily development proportions reach the value of 1 . Numbers of above 1 were considered and depicted as 1 since in biological sense a value above 1 is uninterpretable. The daily development proportion of the total development is the reciprocal of the daily value. The numbers of the reciprocal amounts that provide the value of 1 give the days of the full ontogeny time which is the function of the changing temperature. For example in case of the larval development the number of days can be determine according to the following formula (Eq. 5):

$$
\mathrm{n} \gg \sum_{\mathrm{i}=1}^{\mathrm{n}} \frac{1}{82.171 \mathrm{e}^{-0.101 \mathrm{~T}_{1}}}+\ldots .+\frac{1}{82.171 \mathrm{e}^{-0.101 \mathrm{~T}_{\mathrm{n}}}} \leq 1
$$


where $n$ is the number of days of full larval development; $T 1$ is the mean daily temperature of the first day of the week, when the temperature exceeds the $10.4^{\circ} \mathrm{C}$ value and no longer fall under this value until autumn, $T n$ is the temperature of the $\mathrm{n}^{\text {th }}$ day when the sums of the daily development values reach first or exceed the value of 1 .

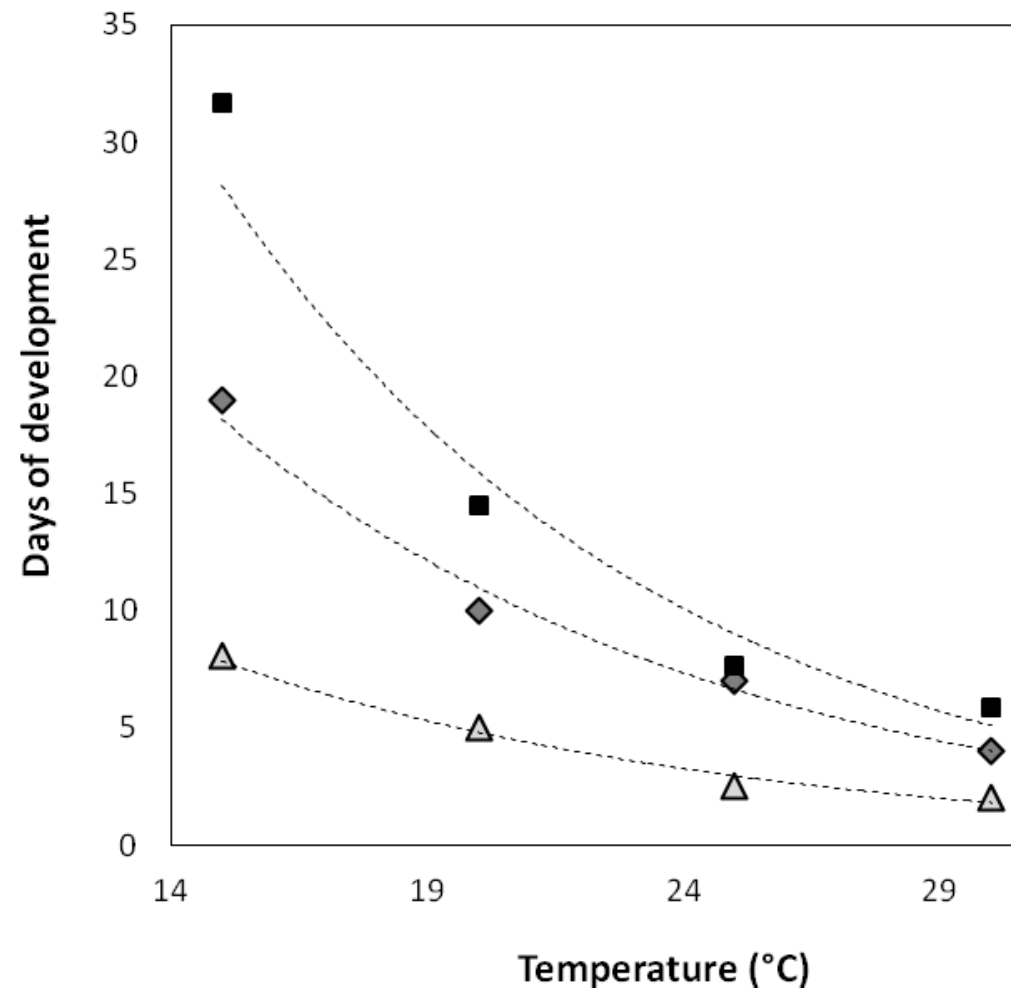

Figure 2. The mean time of the ovule-instar $1^{\circ}$ metamorphosis, the mean cumulative time of the instar $1^{\circ}$ - instar $4^{\circ}$ metamorphosis and the mean time of the pupa-adult metamorphosis under different temperature conditions according to Calado and Silva (2002).

According to the development, the logical order of the calculation line is the following: larval development time, the time of pupation and finally, the time of hatching. It means that a day after that the sums of the daily reciprocal larval development values reach first or exceed the value of 1 , starts the calculation of the development time of pupation, when a day after that the sums of the daily reciprocal pupal development values reach first or exceed the value of 1 starts the calculation of the hatching time and when the sums of the daily reciprocal hatching time values reach first or exceed the value of 1, the ontogeny ended and theoretically the individual is replication competent. Since the aim is to calculate the maximal annual generation number, it was considered to start the calculating of the development a next generation a day after the ending of the previous. The calculation of the sequence become terminated when the daily mean temperature drop below the threshold $10.4^{\circ} \mathrm{C}$ in autumn.

The developments of the generations throughout the year were depicted in one figure. The first part of the curve represents the larval ontogeny, the second the pupal and the third shows the hatching time. The proportion values above 1 were depicted as 1 
in the figures. The starting value is not 0 , since in the activity season of the mosquito each day has a correspondent development value.

\section{Data processing and statistics}

Mood's median test and two sample t-tests were performed using R statistical tool27 to compare the distribution explanatory climatic conditions according to the control (non-successful) and case (successful) trapping sites. We encoded the successful trapping (presence) sites as 1 , the non-successful (absence) sites as 0 . The tests were evaluated at 5\% significance level. Successful (case) and control (unsuccessful) trapping points were marked and used in each of the studied countries. Receiver Operating Characteristic (ROC) curve was drawn and Area under the ROC curve (AUC) value was calculated by pROC module28 of statistical software R. Principal Component Analysis and Hierarchical Clustering Analysis were performed by XLSTAT 10.029 (Adinsoft, 2010)

The geographical data were based on the satellite images of Google Earth ${ }^{\mathrm{TM}} 2013$ application. We used the site appointing function of Google Earth imagery to mark the trapping points. To gain a higher resolution map further (non-trapping) points were involved into the model. Each marked points were named after its status (trapping, nontrapping or other points). We converted the designated spatial data into keyhole markup language $(\mathrm{kml})$ file format type (altitude or gamma intensity data). After opening the $\mathrm{kml}$ data we converted them into shape file format in the ArcGIS 10.1 software. To create the potential annual generation number map of Croatia, Slovenia and Hungary we linked the points with the calculated generation numbers. The different values were assigned into the referred points and were sorted into attribute table. We interpolated the values of the spatial data by the IDW interpolation function of the Spatial Analyst Tool in the ArcGIS.

\section{Climate envelope modeling}

Climate has the greatest influence on the geographical distribution of the species in Europe (Thuiller et al., 2004). To project the current potential range and possible impact of climate change on the distribution of Ae. albopictus, we used the climate envelope modeling (CEM) method (Hijmans and Graham, 2006), which was applied with success earlier by Fischer et al. (2011) to predict the potential expansion of the same species. This modelling approach is based on statistical correlations between the observed ranges of species and environmental variables to define the limiting ecological factors, the climatic requirements (e.g. temperature and precipitation patterns) of the species (Hijmans and Graham, 2006; Guisan and Zimmermann, 2000; Elith and Leathwick, 2009). Using a climate scenario the climate envelope model can characterize the present and predict the potential future distributions of vector species. Important to note, that in the case of some vector-borne infectious diseases long-distance transport of vectors and migration of infected individuals might play a hardly predictable but crucial role as the modifier of the geographical occurrence (Walther et al., 2009). We used three physical (climate) factors averaged in the 30 -years periods: the monthly mean temperature $\left(\mathrm{T}_{\text {mean }},{ }^{\circ} \mathrm{C}\right)$, monthly minimum temperature $\left(\mathrm{T}_{\min },{ }^{\circ} \mathrm{C}\right)$, and monthly precipitation $(\mathrm{P}$, $\mathrm{mm}$ ) of the 12 months. Cumulative distribution functions were calculated by PAST statistic analyzer (Hammer et al., 2001) for the selected $3 \times 12$ climatic parameters $\left(\mathrm{T}_{\text {mean }}, \mathrm{T}_{\min }, \mathrm{P}\right)$. A $10-10 \%$ from the extrema, except the precipitation (we neglected $0 \%$ 
only) in the case of Ae. albopictus were neglected from the climatic values found within the observed distribution (Fig. 3).

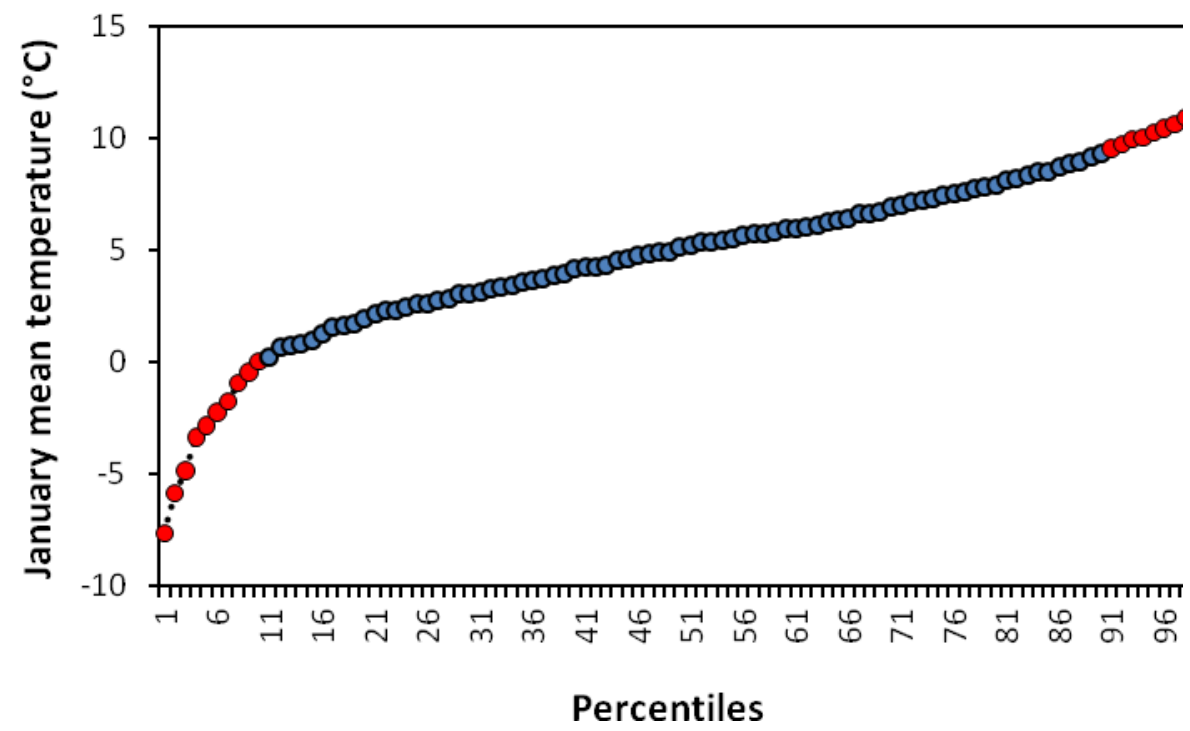

Figure 3. The distribution of the percentiles of the mean January temperature. The 10-10\% from the extrema were neglected (red points).

The selection of the amount of percentiles to be left from the climatic values was based on our former results and elaborations. The aim was to reduce the false positive error of the model result in a reasonable degree. We refined the climatic data by Inverse Distance Weighted interpolation method of ESRI ArcGIS 10 software (ESRI, 2006). The modeling steps were the follows: first, the grid points within the distribution were queried; second, the percentile points of the climatic parameters were calculated; third, the suitable percentiles of the climatic parameters were chosen; fourth, modeling phrases (3 strings) were created by string functions of Microsoft Excel 2007 for the three modeling periods; fifth, the ranges were selected where all the climatic values of the certain period were between the extrema selected in step 3 .

\section{Results}

Number of trapped biting mosquitoes (Culicidae) - A total of 2015 biting mosquito (Culicidae) specimens were collected and identified from the trapped and the incubated material. The major part $(1644 / 2015 ; 81.6 \%)$ of the biting mosquitoes was gained through incubation, and 371 adults $(18.4 \%$ of the total) were trapped at the four trapping sites (Nagyharsány: 33 and 5 Letenye, South-Southwestern Hungary; Zagreb: 12). The incubation was unsuccessful in 4 cases and in 3 cases incubation resulted in less than three specimens. In contrast, in 14 cases the number of the identified biting mosquitoes was more than 25 individuals, while 7 incubations resulted in over 100 adults. Four $A e$. albopictus individuals were collected during this survey: 1 was incubated (Fig. 4A, B), 1 was trapped with a CDC trap, while 2 specimens were collected directly from our skin. Successful collections were restricted to the already known occurrence at the Prečko district of Zabreb, Croatia. Four non-culicid dipterans with vector importance 
(Leishmania infantum), namely Phlebotomus neglectus Tonnoir specimens were trapped in Nagyharsány (Fig. 4C). The identified single Ae. albopictus larva was found in a 60x40 $\mathrm{cm}$ rainwater collector. The dissolved oxygen-content was $6.89 \mathrm{mg} 1-1$ at $22.5^{\circ} \mathrm{C}$ water temperature ( $80.6 \%$ oxygen saturation) with $7.89 \mathrm{pH}, 335 \mathrm{mS} \mathrm{cm}-1$. The water collector stood in a moderately shaded environment close to the edge of the floodplain forest of the river Sava. A female mosquito was captured by hand at the same site (Fig. 4D).
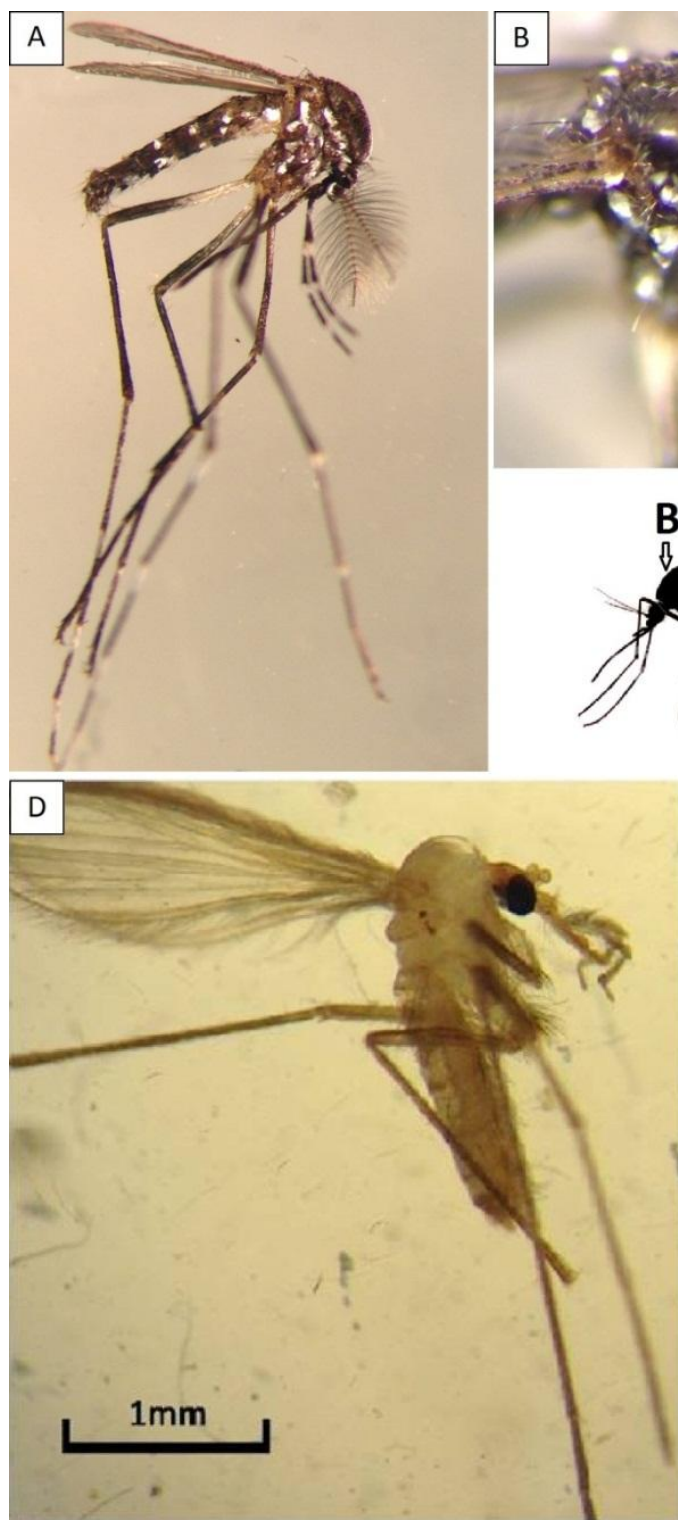
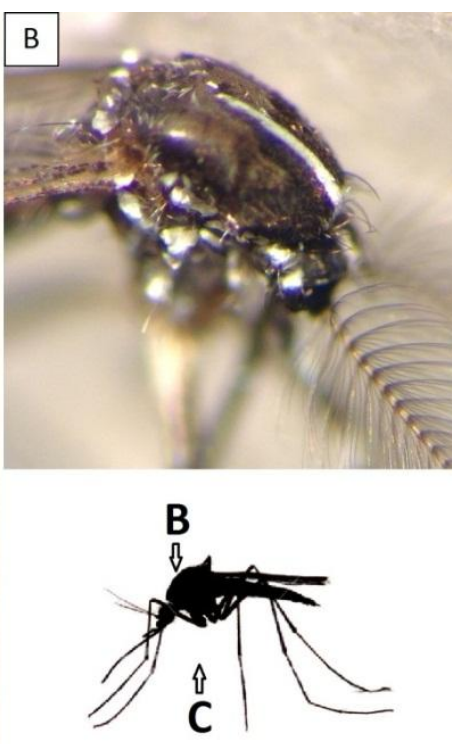
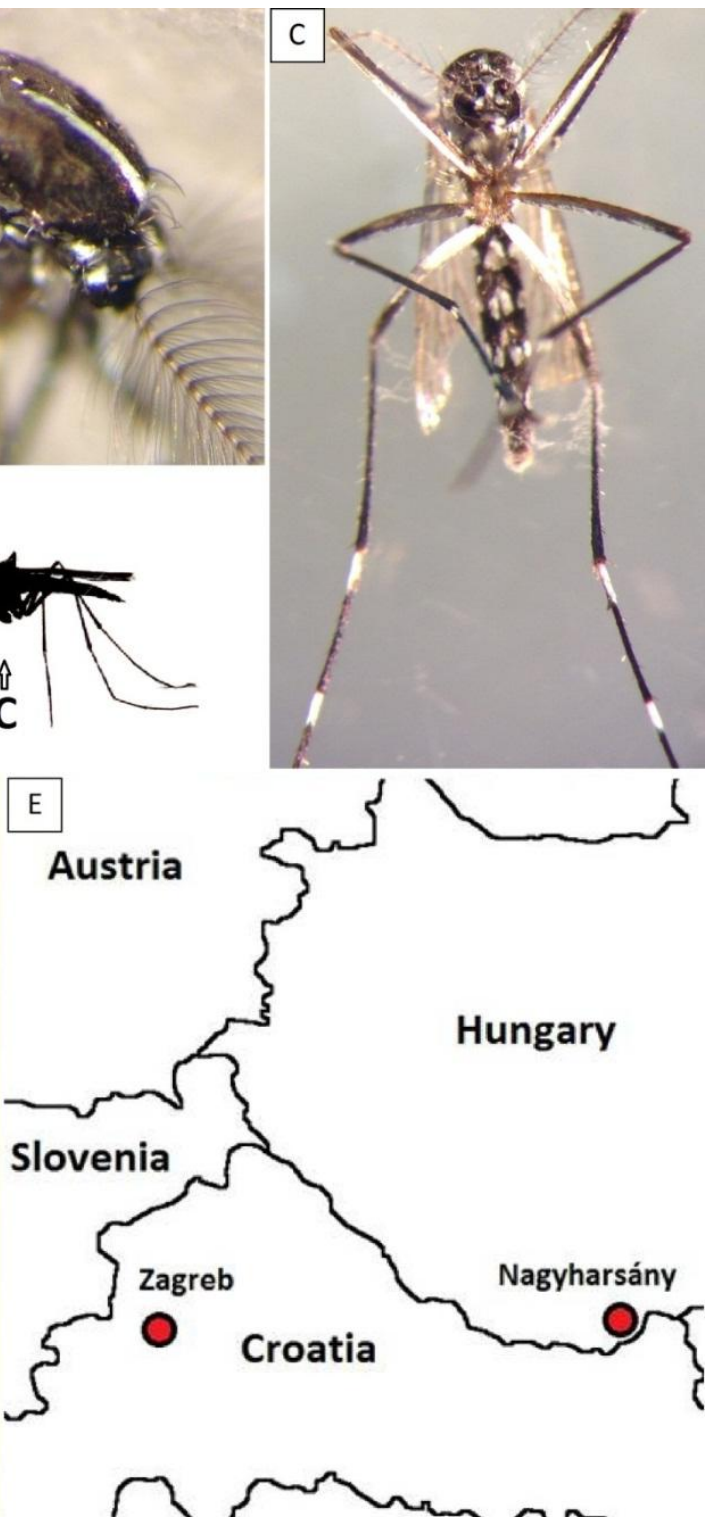

Figure 4A. The right lateral view of a male Ae. albopictus mosquito individual from Zagreb (district Preckko), Croatia. $\mathbf{4 B}$. The single white line on the doro-lateral view of the thorax is characteristic of the Asian tiger mosquito. 4C. the abdominal view of the specimen. 4D. a male Phlebotomus neglectus individual from Nagyharsány, Hungary. $\mathbf{4 E}$. collecting sites of the individuals.

Climatic factors potentially influencing the occurrence -We found a non-significant difference ( $\mathrm{p}=0.3541$ ) between the habited and non-habited trapping sites according to the sum of the July precipitation. The number of the successful trapping sites (presence) was 29; the number of the non-successful trapping sites (absence) was 20 (Fig. 5A). We found 
significant difference $(\mathrm{p}<0.001)$ between the successful and non-successful trapping sites according to the difference of the sum of the July precipitation where the mean minimum January temperatures were under the mean (Fig. 5B). To test the equality of the successful and the non-successful trapping sites according to the January mean temperature, the Mood's median test were used due to the non-normal distribution of the successful (presence) group. The test found a strongly significant difference $(\mathrm{p}<0.0001)$ between the two groups $($ Fig. 5C). To test the equality of the successful and the non-successful trapping sites according to the sum of the autumn and winter precipitation, the Mood's median test were used due to the non-normal distribution of the successful (presence) group. The test found significant difference $(\mathrm{p}<0.001)$ between the two groups (Fig. 5D). We found significant difference $(\mathrm{p}<0.001)$ between the successful and non- successful sites according to the mean of the minimum temperature in January. The number of the successful trapping sites (cases) was 29; the number of the non-successful trapping sites (controls) was 20. The mean of the successful (positive) trapping sites is $-0.1{ }^{\circ} \mathrm{C}$ (SD: 1.7047 ), in case of the unsuccessful (negative) sites is $-1.88{ }^{\circ} \mathrm{C}$ (SD: 1.110; Fig. 5E). We found significant $(\mathrm{p}=0.0185)$ difference between the habited and non-habited sites according to the difference of the mean of the January minimum temperature under mean of the minimum July sum of precipitation (Fig. 5F).

The results of the ROC analysis of the sum of the July precipitation where the following: true negative: 12 , false negative: 10 , true positive: 19 , false positive: $8 ; \mathrm{n}_{\text {cases }}=29, \mathrm{n}_{\text {controls }}=20$, auc $=0.5594$, power $=0.1079$. The best cut point is at $66.14 \mathrm{~mm}$ July precipitation according to the positive and negative condition values (Fig. 6A). The results of the ROC analysis of the mean minimum temperature in January where the following: true negative: 17, false negative: 7 , true positive: 22 , false positive: $3 ; \mathrm{nc}_{\mathrm{ases}}=29, \mathrm{n}_{\text {controls }}=20$, auc $=0.7629$, power $=0.9194$. The best cut point is at $-1.2{ }^{\circ} \mathrm{C}$ January mean minimum temperature according to the positive and negative condition values (Fig. 6B).

Climate related habitat characteristics of Ae. albopictus - The difference from the average of the mean minimum January temperature (abscissa) and the difference from the average of the mean July precipitation (ordinate) of the studied sites for the period of 2000-2014 were depicted in a Cartesian-like coordinate system. Although the successful trapping sites overlap the humid subtropical climate $(\mathrm{Cfa})$, the (Csa) warm Mediterranean climate, the cool oceanic climate $(\mathrm{Dfc})$ and the $(\mathrm{Cfb})$ temperate oceanic climate, as well as the (Dfb) temperate continental climate/humid continental climate. Most of the unsuccessful trapping sites are positioned in the lower left quadrant of the diagram (where the sites with colder winters and dryer summers of the temperate continental climate/humid continental climate (Dfb) according to the Köppen-Geiger climatic categories (Fig. 7A) are represented. The difference from the average of the mean minimum January temperature (abscissa) and the difference from the average of the sum of the autumn and winter precipitation (ordinate) of the studied sites for the period of 2000-2014 show a greater separation of the successful and nonsuccessful sites (Fig. 7B). The studied trappings were performed in 3 major climate ranges of the North Balkan Peninsula according to the Köppen-Geiger climatic classification: in the Mediterranean coastline category which consists of the Cfa and the Csa climates, the Mediterranean Mountains which includes Dfc and the Cfb climates, as well as the (Dfb) continental climate. Ae. albopictus can be found in the Mediterranean Mountains and the Mountains of the Balkans (19 of the studied sites) and the Mediterranean coastline (15 of the studied sites) and only one habitat of the Asian Tiger mosquito established under continental climatic conditions (Zagreb; Fig. 7C). The difference from the average of the mean minimum January temperature (abscissa) and the difference from the mean of the sum of the autumn 
and winter precipitation (ordinate) of the studied sites for the period of 2000-2014 show a greater separation of the different climate points (Fig. 7D).
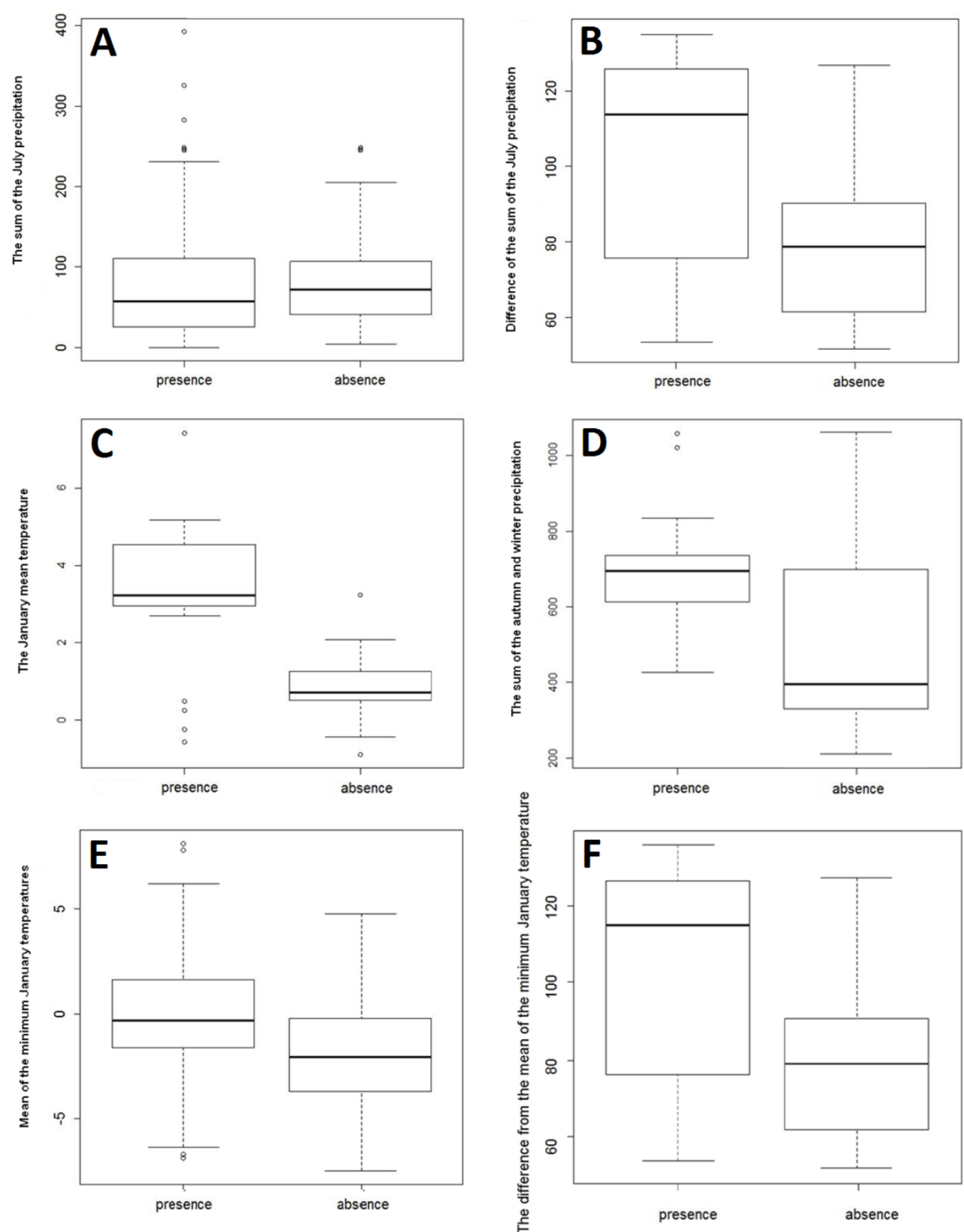

Figure 5A. Successful (presence) and the non-successful (absence) trapping sites according to the sum of the July precipitation; $\mathbf{5 B}$. the difference from the sum of the July precipitation in sites where the mean January temperature were under the mean; $5 \mathrm{C}$. the January mean temperature; $\mathbf{5 D}$. the sum of the autumn and winter precipitation; $\mathbf{5} \boldsymbol{E}$. the mean of the minimum January temperatures; $\mathbf{5 F}$. the difference from the sum of the mean minimum January temperatures in sites where the sum of July temperatures were under the mean. 

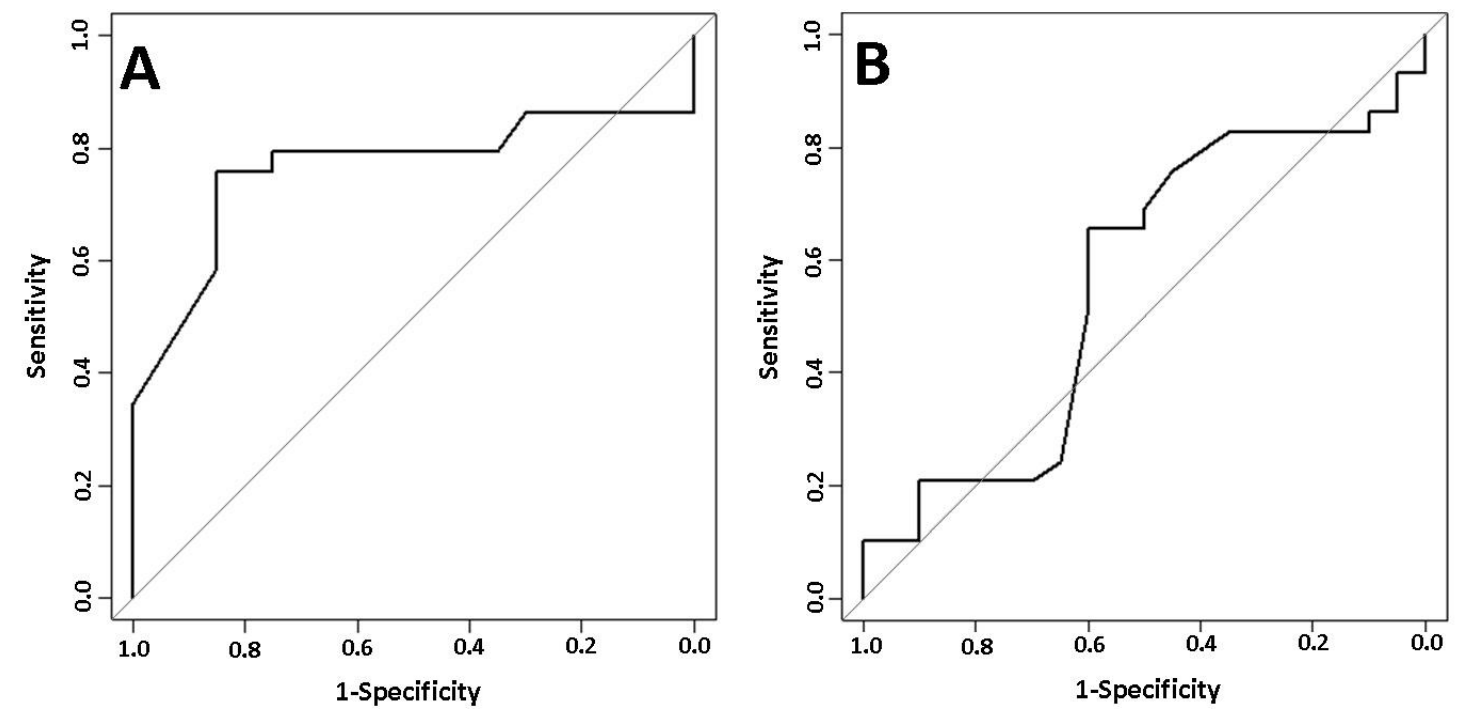

Figure 6A. The receiver operator characteristic curves of the mean minimum temperature in January and $\mathbf{6 B}$. the sum of the July precipitation.
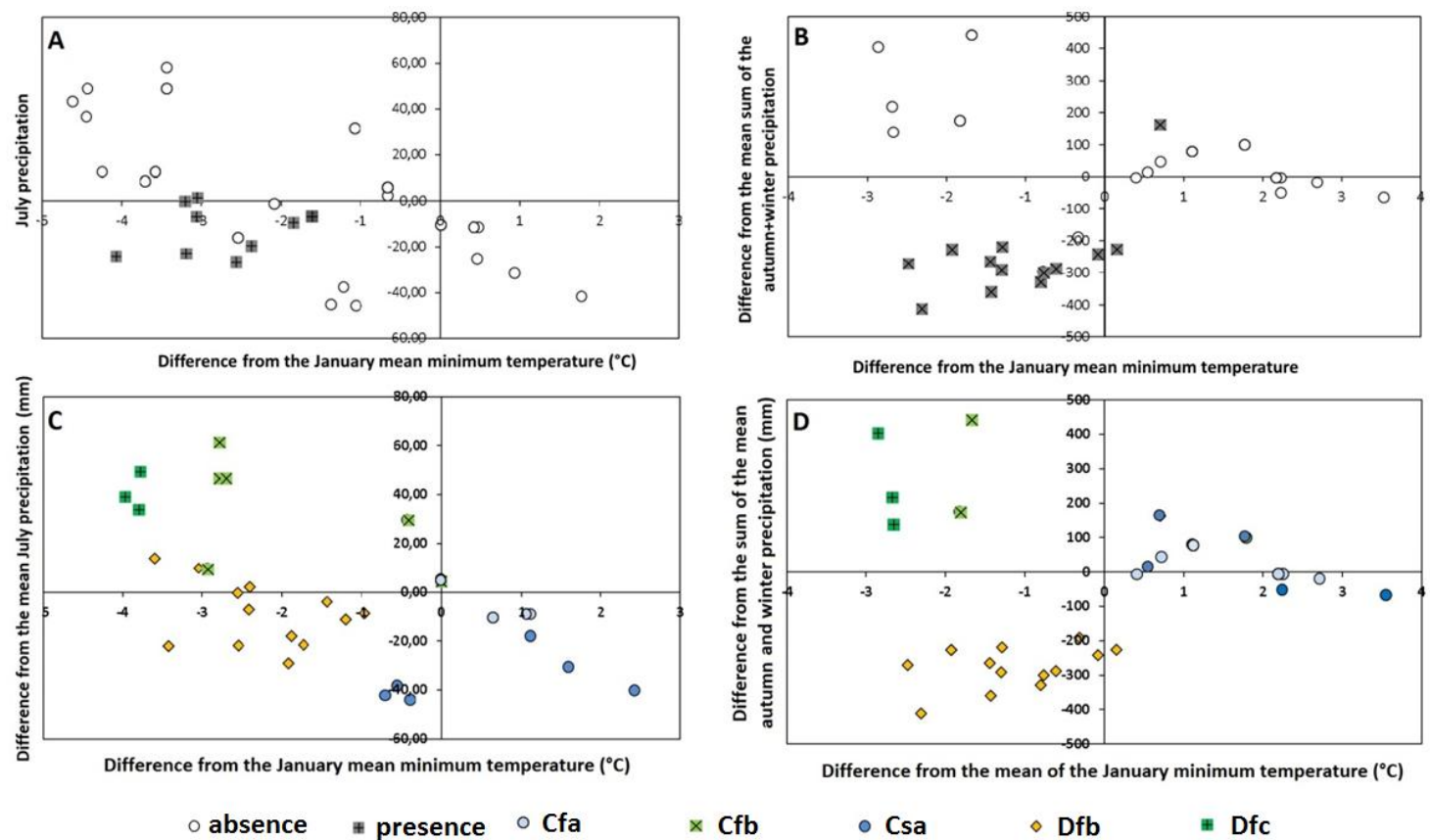

Figure 7A. The successful and the abortive trapping sites according to the scales of July precipitation and the difference from the mean January minimum temperature, $7 \boldsymbol{B}$. sum of the difference from the sum of the mean autumn and winter precipitation and the difference from the January mean minimum temperature, 7C: The Köppen-Geiger climates of the sites according to the difference from the mean July precipitation and the January mean minimum temperature or 7D: the sum of the mean autumn and winter precipitation and the difference from the mean of the January minimum temperature.

Cluster Analysis was used to group the positive and negative collecting/trapping sites according to the following climatic factors: January mean temperature $\left({ }^{\circ} \mathrm{C}\right)$, mean 
minimum January temperature $\left({ }^{\circ} \mathrm{C}\right)$, mean July precipitation $(\mathrm{mm})$ and sum of the autumn and winter precipitation. According to the Cluster Analysis there are three significant distinctive climatic groups in the studied area: 1) continental temperate climate including most of the inland sites in Croatia and Hungary with only one successful trapping site, furthermore the 2) Mountainous Mediterranean climate including some sites in the valleys of the Julian Alps in Slovenia and 3) coastal Mediterranean climate sites in Slovenia and Croatia with several successful trapping sites (Fig. 8A). The $2^{\text {nd }}$ climate group is the sister group of the 3 rd and except ones sites positive sites belong to these climatic groups. The $3^{\text {rd }}$ climate groups have two subgroups: a colder and warmer coastal Mediterranean one. The Cluster Analysis put the climate of the coastal Mediterranean group next to the group of Mountainous Mediterranean. In the Principal Component Analysis the above found four major distinguishing variables were used. The results are confirmed, since the planes stretched by the first and second components are responsible for the $51.85 \%$ (sum of the mean precipitation) and $36.43 \%$ (mean January minimum temperature), in all $88.28 \%$ of the variance. The result of PCA proved the former statistical conclusions (Fig. 8B).
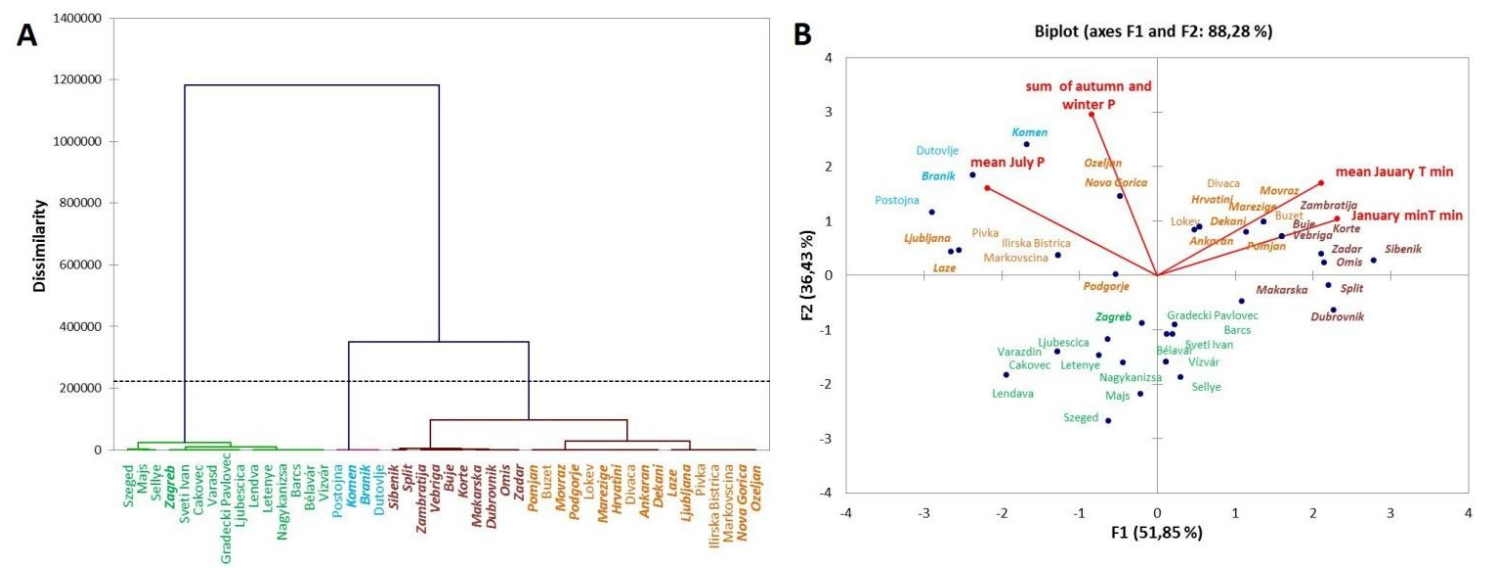

Figure 8. The results of $H C A(8 \boldsymbol{A})$ and $P C A(8 \boldsymbol{B})$ based on the winter and autumn precipitation sums, the mean annual precipitation sums, the January mean minimum temperature and the January minimum temperature values. Trapping and reference settlements of the grids were colored according to the color of the corresponding climatic strains. Positive trapping or larva collecting sites were marked with bold, italic letters. Orange: Cfa, blue: Cfb, brown: Csa, green: Dfb climates according to the Köppen-Geiger climate classification system.

According to the biplot displaying the four major variables it can be stated that 1) the cluster of the Mediterranean climate types are segregated from the continental type mainly both by cold winters and dry summers; 2) the positive difference of the variables are reliable for the presence of Ae. albopictus in the given sites and the negative differences for the absent of the mosquito in most of the cases and 3) a temperature or a precipitation-type variable itself cannot explain the presence/absence status of the mosquito in a given area. The variables of the successful trapping and/or collecting sites are bound mainly to the coastal Mediterranean territories of the northern Adriatic area. In the continental climate Zagreb was the only positive site for the occurrence of $A e$. albopictus, although the winters in Zagreb are milder than in case of the continental areas of Slovenia and Hungary. The outputs of cluster and principal component analysis 
are confirmed the results of the analysis of 1 to 1 climatic factors characterized by the areas according to the Köppen-Geiger climate zones.

\section{The potential annual generation numbers}

The mean number of the potential generations in the successful trapping sites is 4.33 per year in the coastal areas, 3.61 per year in the mountainous areas and 3.52 per year in the solo continental site, Zagreb. The difference between the generations of the successful and non-successful sites were no significant $(\mathrm{p}=0.2902)$. According to the one-way variance analysis there are significant $(\mathrm{p}<0.05)$ differences between the potential generations of studied coastal $(n=14)$ and mountainous $(n=19)$, respectively the coastal and the continental $(n=15)$ trapping sites and there are non-significant ( $p>0.05)$ difference between the mountainous and the continental trapping sites, whether the given trapping site was successful or not. We found significant difference $(p<0.05)$ between the potential generations of the successful coastal $(n=14)$ and the mountainous $(n=12)$ trapping sites. The single successful continental trapping site of Zagreb was not involved to the analysis. The interpolated map of the potential number of generations predict 4-5 generations per year in the southern Mediterranean coastline of Croatia and Istria, similar number was also calculated for the continental parts of Croatia and the main part of Hungary (Fig. 9).

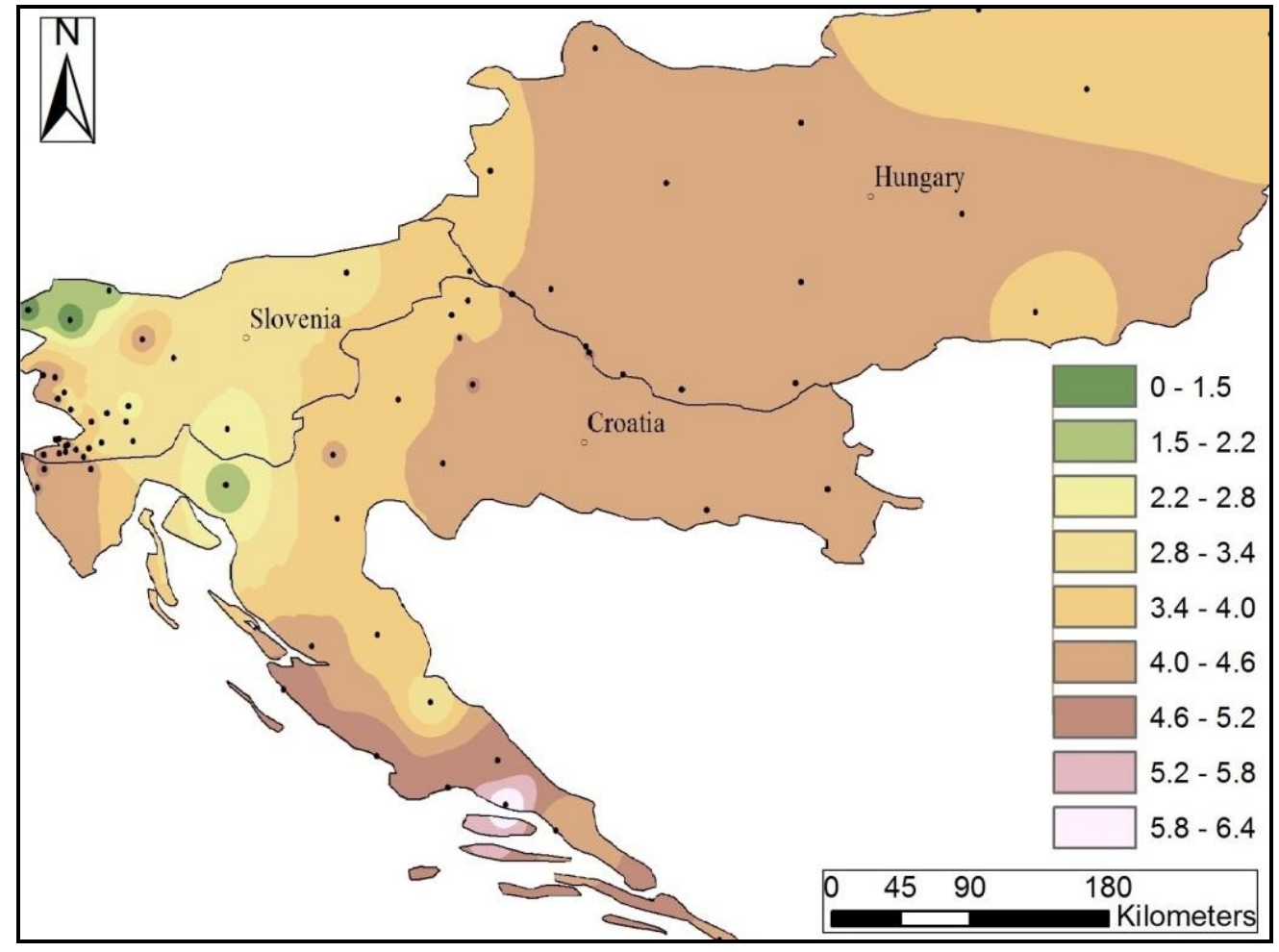

Figure 9. The potential number of the annual generations of Aedes albopictus according to the mean monthly temperatures of the trapping and the additional points in 2000-2014.

It was found that recently five completed generation is possible in Hungary. The mean diapausing time between the generations of two years is 161 days (about 5.3 months). The potential season of the mosquito could takes 204 days (about 6.7 months) 
in the area. The mean times of the larval developmental times are 26, 14, 9, 9, 10 and 20 days in the order of the annual generations. The mean time of the pupal ontogeny stage is $26,14,12,12,14$ days and the sixth cannot be completed. The mean hatching times are $6,5,4,4,7$ and the sixth one cannot be achieved in the same year. The time of the full developments are take 58, 33, 25, 25 and 36 days in the order of the annual generations (Fig. 10).

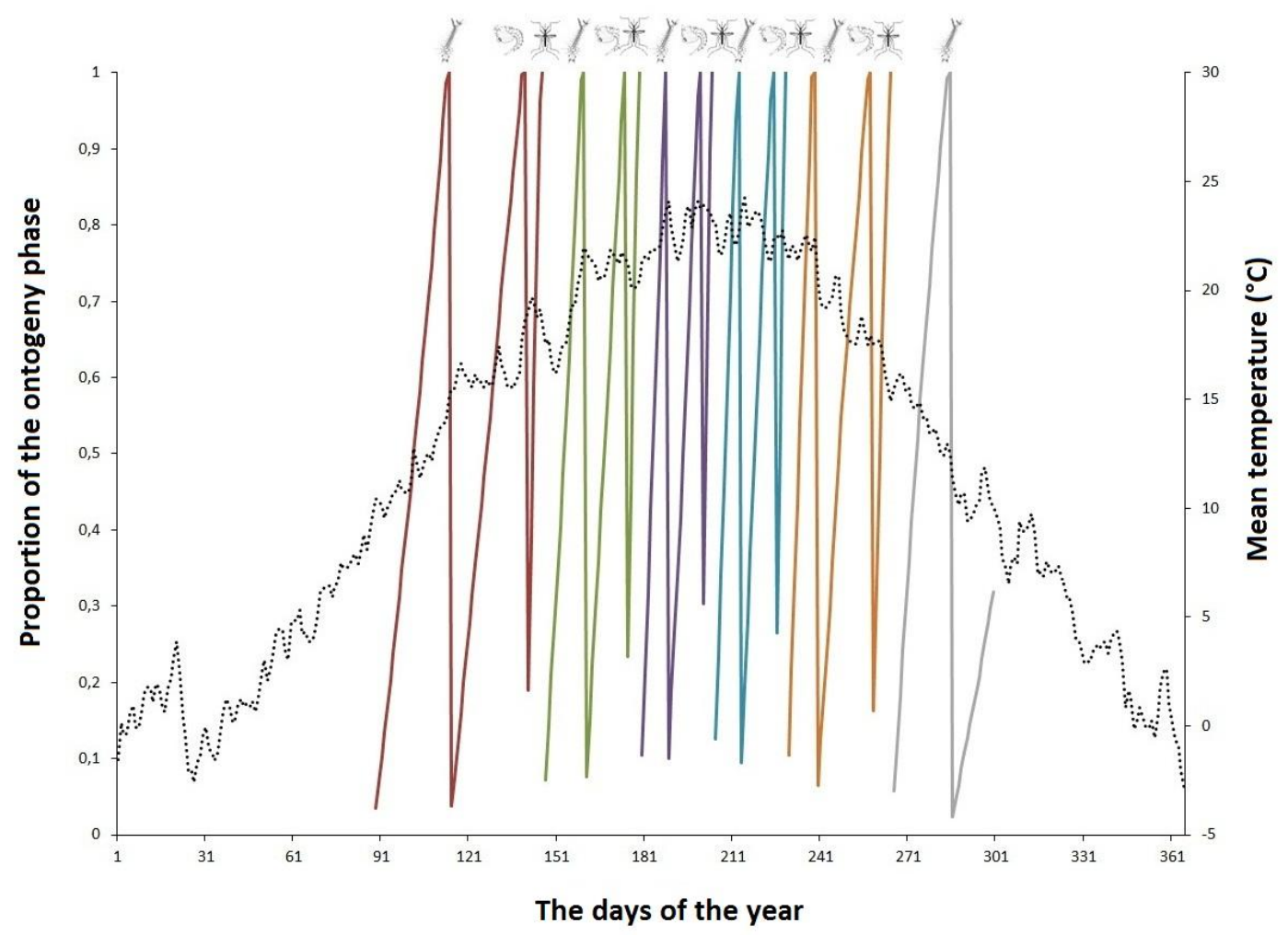

Figure 10. The modeled generations of Aedes albopictus in Hungary. The pictograms show the current ontogeny stages.

\section{Climate envelope modelling}

The modeled recent potential occurrence of Ae. albopictus includes the observed range of the species and contains a large part of the Carpathian Basin and the whole Northern Balkan Peninsula. It was found, that the January mean temperature and the July precipitation are determining the northern expansion of the mosquito in the eastern Mediterranean Basin. The model predicts the expansion near the northern borders of the distribution in the studied region for the period of 2011-2040 and 2041-2070. The modelled potential occurrence of the mosquito shows that the environmental conditions are permissive for the mosquito in the entire Northern Balkan and the south-western parts of Hungary even in the present period. However the model properly outlined the line of the Alps as the boundary of the northern expansion in the north-western edge of the area, no limiting effect of the Mediterranean mountain region was represented. The model suggests that the potential further invasion to the Carpathian Basin of the species can occur from Slovenia, Croatia or Serbia. Geographically the known living habitat in Zagreb is the nearest initial point of the mosquito to the Hungarian border (Fig. 11). 


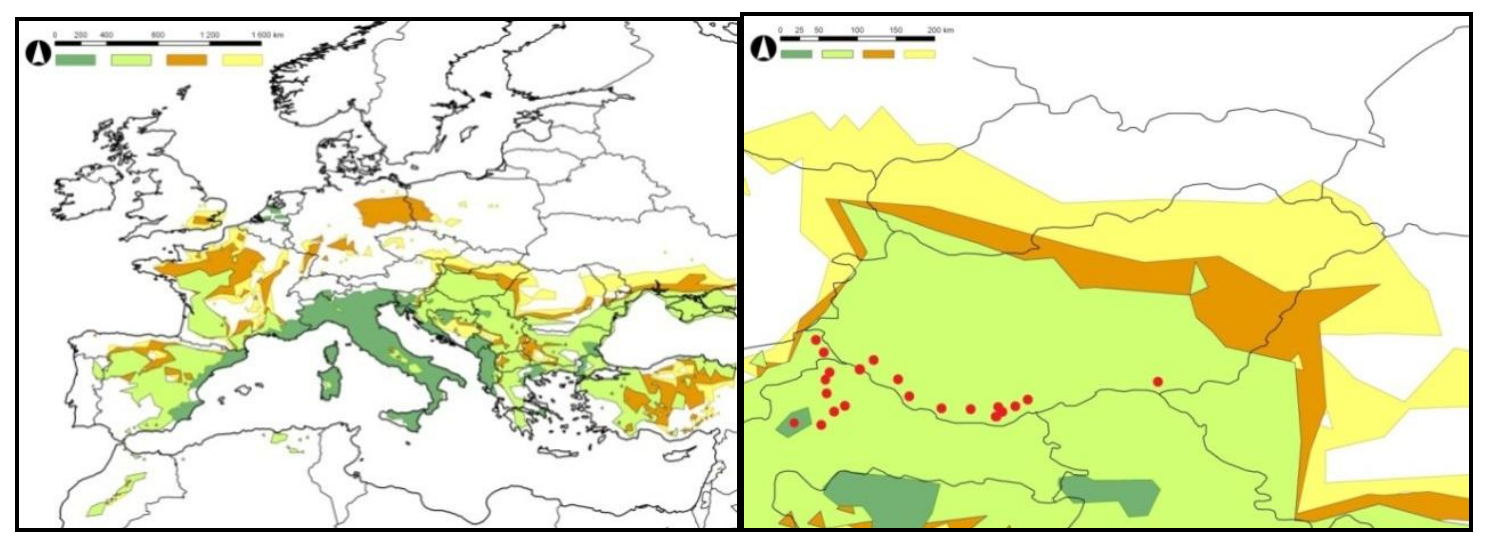

Figure 11. The recent (2012) distribution of Ae. albopictus mosquito according to the European occurrence of the species survey (modified model results of Trájer et al. 2013; dark green according to the VBORNET database, 2013), the potential distribution area for the reference period (1961-1990, light green), the projected future distribution for the period of 2011-2040 (orange) and 2041-2070 (yellow) in Europe and the Carpathian Basin. Red points mark the sampling sites of ours.

\section{Discussion}

According to the previous results of a multi-criteria decision based analysis, the limiting lower thermal suitability thresholds of the distribution of Ae. albopictus in the winter season are the $-1{ }^{\circ} \mathrm{C}$ January mean temperature (ECDC, 2015). We found that the January mean minimum is a better differentiator between successful and non-successful trapping sites than the January mean temperature. It was found that $-1.2{ }^{\circ} \mathrm{C}$ January minimum temperature is the cut point of the presence and the absence of the mosquito. However, in Slovenia, the Asian tiger mosquito is present in localities where the winter minimum temperatures can approximate $-4^{\circ} \mathrm{C}$ in January. Our findings could be consistent with the statements of the previous studies which found that daily mean $0^{\circ} \mathrm{C}$ January isotherm is the limit of the overwintering potential of the species and the limit of $-5^{\circ} \mathrm{C}$ isotherm is the limit of summer expansion range (Hawley et al., 1989; Nawrocki and Hawley, 1987). It is difficult to determine the lowest survivable January temperature for this mosquito, since in higher latitudes, Ae. albopictus spends the winter month's diapausing in the egg stage and only if the temperature goes below a certain level, will the first stage larvae in these eggs die. Hawley et al. (1989) described how prolonged cold and photoperiod induced diapause can increase the overwintering ability of Ae. albopictus eggs. It is easier to explain the effect of the July drought on the occurrence. It is known that Ae. albopictus is much more resistant to severe desiccation than e.g. forest Aedes species the high temperatures and dry conditions of this summer month can cause high levels of mortality even in non-diapausing eggs (Sota and Mogi, 1992). An important result of our analysis is that the January minimum temperature cannot explain the observed distribution since in mountainous areas Ae. albopictus can only persists at sites where the sum of precipitation is more than about $60-70 \mathrm{~mm}$ in July. Neither the July precipitation, nor the sums of the autumn and winter precipitation alone is the differentiator of the presence and the absence of the mosquito. July precipitation over $66 \mathrm{~mm}$ has a positive effect on the presence of the Asian tiger mosquito. 
The Varaždin Mountains (North Croatia) due to its topographically low altitudes does not constitute an affective barrier against the expansion of the species. Sporadic and occasional occurrences are possible anywhere due to cargo transport, but a sporadic, single occurrence does not mean that the mosquito is established in the area. Either a single occurrence does not assume even the climatic suitability of an area, because the species can reproduce during one summer. It is possible to find the individuals of a species in a causal occasion since the field collector trips are typically organized during the summer season. It is no coincidence that in the vector maps the following categories of the occurrences and observations were distinguished: established, introduced, absent, no data. A good example for this case that in the $2015^{\text {th }}$ year of the Asian tiger mosquito maps of V-BORNET mosquito maps a single introduced occurrence of Ae. albopictus can be seen in the southern part of the Hungarian Great Plain (ECDC, 2015). Since this causal occurrence does not mean the overwintering ability of the species, this data was neglected from the climatic analysis.

The fluctuating phenomena of the observation is visible in the trapping data of the mosquito e.g. in Belgium where local environmental conditions made the establishment possible (Schaffner et al., 2004) or in the Netherlands where the Asian tiger mosquito resides in horticultural companies and it was most likely introduced from China by a Dracaena plant (Asparagaceae) cargo (Scholte et al., 2007). In Croatia, even in the coastal areas of the Adriatic Sea, where the presence of the Asian tiger mosquito was demonstrated to be continuous, effective catching sites show fluctuation (which also depends on the trapping activity). It is similar to that found in Zagreb, where the species was first observed in 2004, later in 2005, but not in 2006, while it was collected again in 2007 (Merdić, 2011). Nevertheless, even the remarkable occurrence of the species in Zagreb is quite curious since the nearest distribution area is the Adriatic coastal part of Croatia. These observations support the idea that the absence of Ae. albopictus during our collecting expedition provides an indicative rather than strictly conclusive result with regard to the absence of the established populations of the species in the studied area. According to Knudsen et al. (1996) the $0^{\circ} \mathrm{C}$ mean winter temperature is one of the most important criteria of the overwintering of Ae. albopictus in Europe. This might be consistent with the fact that Zagreb lies on/within the $0^{\circ} \mathrm{C}$ January isotherm. An important result of our study that results of climatic analysis may esteem only the established occurrences of the species, although causal, single introduced occurrences cannot be predicted.

According to the PCA and HCA analyses the climate of the continental areas form a markedly different climatic group both from the coastal and the mountainous Mediterranean sites. The only positive, but isolated, but established continental habitat Zagreb belongs to a same group with the typical continental points of Hungary, Croatia and Slovenia. In order to evaluate this information, we need to mention that climatic values were averaged for $0.25^{\circ}$ grids which cover a relatively extended area. Since Zagreb itself is surrounded north by Mèdvednica mountain, it is clear that both the climate of the Sava valley, the mountainous climate of the Mèdvednica (the highest peak is 1,035 meters above sea level) and the climate of the city were averaged in its grid. In addition, it is likely that the urban heat effect of Zagreb and the warmer climate of the south slopes make the humid continental climate of the capital of Croatia warmer than the surrounding areas due to anthropogenic heat emission. Urban heat island effect can explain similarly the presence of Ae. albopictus in Zagreb to the case of the also 
isolated occurrence of Ph. neglectus in the agglomeration of the Hugarian Capital due to the urban heat effect (Trájer et al., 2014).

It is particularly important to mention the finding (which was also indicated by our results), that since its first record in Zagreb the mosquito has not become a very common element of the mosquito fauna in the neighboring eastern and northern Northern Balkan areas. Köppen-Geiger type biozone characteristics support the presence of Ae. albopictus in the studied area. In general, warm oceanic or humid subtropical, temperate oceanic and warm Mediterranean climate might be permissive for the Asian tiger mosquito, while the temperate continental climate is not. Based on our results, the Asian tiger mosquito has not yet spread further from the site of its first observation in Zagreb, but became a constant contributor to the local mosquito fauna. However, the recent situation in the region of the northern Balkans is very similar to the peripheral occurrence of the species in the United States, where beyond the continuous distribution border; the sporadic occurrence of the mosquito is mainly associated with large cities and extends far into the non-permissive inland areas of the country (Moore and Mitchell, 1997). Ae. albopictus invaded the state of Florida in only 6 years in 19871993 executing a cca. $600 \mathrm{~km}$ linear spread (O'Meara et al., 1995), meaning a remarkable $100 \mathrm{~km}$ linear expansion capability annually. Although the climate of Florida is milder than that of the northern Balkan's, the cca. $90 \mathrm{~km}$ distance between the stable occurrence of the mosquito in Zagreb and the wet floodplain of Hungarian border is a justified reason for future vigilance and monitoring. Several other authors also predict the potential continuous occurrence or the presence in Hungary of the Asian tiger mosquito e.g. Fischer et al. (2014) predicted about 0.41-0.6 climatic suitability in the period of 2011-2040 for the larger part of Hungary. Concerning the effect of the combination of heavy cargo transport and climate suitability, Thomas et al. (2014) found the North Balkan Peninsula especially vulnerable. Our trapping results and climatic analysis did not contradict the results of climatic models. It is also likely that Ae. albopictus as a typical invasive species has not yet filled the entire suitable area of the North Balkans and Carpathian Basin.

We also need to mention the limitations of our study. Since Ae. albopictus is an invasive, non-native species in the studied area it is likely that the mosquito does not fill the entire suitable area in climatic sense. Modeling results suggest that the climate of Transdanubia, Hungary could be suitable for the species (Fischer et al., 2014, Trájer et al., 2014). In contrast to the model results there are only few known established occurrences of Ae. albopictus in the continental areas of Europe. Based on the model results of Fischer et al. (2014), Ae. albopictus mainly live in areas where the climatic suitability value for the mosquito is more than 0.41 . The climatic suitability of Transdanubia for Ae. albopictus was about 0.21-0.40 according to the climatic conditions in the end of the $20^{\text {th }}$ century. Although, the used mosquito distribution data of this study were based on collecting and trapping activities which were performed in the first and the second decades of the $21^{\text {st }}$ century, the current observed established distribution of the mosquito corresponds to the modeled one of Fischer et al. (2014) based on the climate of the end of the 20th's.

Due to the fact that each site was sampled on only one date and the overall period for this intensive survey was limited to 4 days (8.17.14 to 8.20.14). We acknowledge that the conclusion that the mosquito is really absent in the case of a given location, would require more systematic sampling. Even so, the probability of abundance for a wider studied area is also low if the species was not collected from any sampling site. In 
contrast, the mosquito was immediately found in the known occurrence of Zagreb by different collecting techniques. In some cases only one container or water body was sampled per site. At six of the sites sampling was conducted on groundwater pools, which are microhabitats that seldom harbor Ae. albopictus larvae. Since the mosquitoes were reared to the adult stage for species identification, some individuals surely died before reaching the adult stage.

Some sites or areas with Ae. albopictus occurrences of the additional data may be listed as negative due to inadequate or improper sampling activities. It cannot be excluded either that the additional trapping data may be plagued with some of the same type of limitations as the present collecting survey, this kind of limitation may be valid for any mosquito occurrence record in the world. On the other hand, sites designated positive for Ae. albopictus, as a result of sampling endeavours, may represent very temporary or permanent populations.

For a correct estimation of the potential spread of Ae. albopictus into new regions, it would be important to be able to distinguish these two population types. Unfortunately data for accomplishing this task is often unavailable. To avoid this pitfall we mixed the occurrence data of Ae. albopictus in Croatia of 4 different years and aimed to reach a relatively frequent sampling around the Croatian-Hungarian border area. Naturally, the selected incidental collections from neighbouring countries do not give a complete picture of the "ecological plasticity" of this species which is why we know our findings for the studied area to be valid. Last, but not least our trapping results confirm the previously observed occurrence (Farkas et al., 2011) the important vector of Leishmania infantum, the sandfly Phlebotomus neglectus in Nagyharsány, South-western Hungary.

\section{Interpretation and conclusion}

Trappings provided important additional information for the clarification of the climatic requirements of the Asian tiger mosquito by representing the relatively dry and cold winters of the North Balkan and South Pannonian continental region. Our results provide a strong indication that the mean of the minimum January temperature was an important determinant of the northern expansion of Ae. albopictus in the reference period. Dry summers and cold winters in the continental parts of the area recently provided relatively unfavorable conditions for Ae. albopictus in the past that has changed due to climate change. It was found that Ae. albopictus can tolerate the relatively low absolute temperature values under wet winter conditions of the Mediterranean mountainous regions. Temperature pattern cannot limit the current spread of Ae. albopictus in the South Pannonian ecoregion. Our climate envelope model result predicts a more extensive current potential distribution for Ae. albopictus compared with our observations; however the model predicted correctly the suitability of the climate of the Mediterranean mountains for the mosquito. The analysis of the climate of the successful and non-successful trapping sites showed a complex conditionality of the habitat preference of Ae. albopictus, however the coexistence of dry summers and cold winters under continental climatic conditions does not seem to be preferable for the mosquito. Ae. albopictus can tolerate the climate of the Mediterranean mountainous region where the relatively cold winters are associated with high annual precipitation. The calculation of the potential number of the annual generations of $A e$. albopictus showed that climate would allow the similar high speed spread of the mosquito in the Carpathian Basin as in the northern Adriatic coasts due to the relatively 
long and warm summers. The number of the generations between the successful and non-successful trapping sites cannot explain the presence of the mosquito in the area.

Acknowledgements. The research was supported by the projects TÁMOP-4.2.1/B-09/1/KMR-2010-0005 and TÁMOP 4.2.2.A-1/1/KONV-2012-0064 1.1. The ENSEMBLES data used in this work was funded by the EU FP6 Integrated Project ENSEMBLES (Contract number 505539) whose support is gratefully acknowledged. We would like to say thank for Máté Vass (University of Pannonia) for the stereomicroscopic images and Borbála Tánczos who helped in the field survey.

\section{REFERENCES}

[1] Adinsoft, S. A. R. L. (2010): XLSTAT-software, version 10. Addinsoft, Paris, France.

[2] Benedict, M. Q., Levine, R. S., Hawley, W. A., Lounibos, L. P. (2007): Spread of the tiger: global risk of invasion by the mosquito Aedes albopictus. - Vector-borne and zoonotic diseases 7(1): 76-85.

[3] Bocková, E, Kočišová, A, Letková, V. (2013): First record of Aedes albopictus in Slovakia. - Acta Parasitologica 58(4): 603-606.

[4] Bonilauri, P., Bellini, R.. Calzolari, M., Angelini, R., Venturi, L., Fallacara, F., Cordioli, P., Angelini, P., Venturelli, C., Merialdi, G., Dottori, M. (2008): Chikungunya virus in Aedes albopictus, Italy. - Emerging Infectious Diseases 14(5): 852-854.

[5] Calado, D. C., Silva, M. A. N. D. (2002): Evaluation of the temperature influence on the development of Aedes albopictus. - Revista de Saúde Pública 36(2): 173-179.

[6] Caminade, C., Medlock, J. M., Ducheyne, E., McIntyre, K. M., Leach, S., Baylis, M., Morse, A. P. (2012): Suitability of European climate for the Asian tiger mosquito Aedes albopictus: recent trends and future scenarios. - Journal of the Royal Society Interface, rsif20120138. [online publication]

[7] Cancrini, G,. Frangipane, di Regalbono, A., Ricci, I., Tessarin, C., Gabrielli, S., Pietrobelli, M.. (2003): Aedes albopictus is a natural vector of Dirofilaria immitis in Italy. - Veterinary parasitology 118(3): 195-202.

[8] Delatte, H., Gimonneau, G., Triboire, A., Fontenille, D. (2009): Influence of temperature on immature development, survival, longevity, fecundity, and gonotrophic cycles of Aedes albopictus, vector of chikungunya and dengue in the Indian Ocean. - Journal of medical entomology 46(1): 33-41.

[9] ECDC (2015): In: Mosquito Vector Maps: Aedes albopictus http,//ecdc.europa.eu/en/healthtopics/vectors/vector-maps/Pages/VBORNET_maps.aspx (accessed in 30 July 2016)

[10] Elith, J., Leathwick, J. R. (2009): Species Distribution Models: Ecological Explanation and Prediction Across Space and Time. - Annual Review of Ecology, Evolution, and Systematics 40(1): 677-697.

[11] ESRI (2006): ArcGIS 10.

[12] Farkas, R., Tánczos, B., Bongiorno, G., Maroli, M., Dereure, J., Ready, P. D. (2011): First surveys to investigate the presence of canine leishmaniasis and its phlebotomine vectors in Hungary. - Vector-borne and zoonotic diseases 11(7): 823-834.

[13] Fischer, D., Thomas, S. M., Neteler, M., Tjaden, N. B., Beierkuhnlein, C. (2014): Climatic suitability of Aedes albopictus in Europe referring to climate change projections: comparison of mechanistic and correlative niche modelling approaches. Eurosurveillance 19(6): pii-20696.

[14] Fischer, D., Thomas, S. M., Niemitz, F., Reineking, B., Beierkuhnlein, C. (2011): Projection of climatic suitability for Aedes albopictus Skuse (Culicidae) in Europe under climate change conditions. - Global Planet Change 78(1): 54-64. 
[15] Gatt, P., Deeming, J. C., Schaffner, F. (2009): First records of Aedes (Stegomyia) albopictus (Skuse) (Diptera: Culicidae) in Malta. European Mosquito Bulletin;27(2009): 56-64.

[16] Giatropoulos, A., Emmanouel, N., Koliopoulos, G., Michaelakis, A. (2012): A study on distribution and seasonal abundance of Aedes albopictus (Diptera: Culicidae) population in Athens, Greece. - Journal of Medical Entomology 49(2): 262-269.

[17] Guisan, A., Zimmermann, N. E. (2000): Predictive habitat distribution models in ecology. - Ecological modelling 135(2): 147-186.

[18] Grard, G., Caron, M., Mombo, I. M., Nkoghe, D., Ondo, S. M., Jiolle, D., Fontenille, D., Paupy, C., Leroy, M. E. (2014): Zika virus in Gabon (Central Africa)-2007: a new threat from Aedes albopictus? - PLoS Neglected Tropical Diseases 8: e2681.

[19] Gratz, N. G. (2004): Critical review of the vector status of Aedes albopictus. - Medical and Veterinary Entomology 18(3): 215-227.

[20] Hammer, K., Harper, D. A. T., Ryan, P. D. (2001): PAST: Paleontological statistics software package for education and data analysis. - Palaeontologia Electronica 4: 9.

[21] Hawley, W. A., Pumpuni, C. B., Brady, R. H., Craig, G. B. (1989): Overwintering survival of Aedes albopictus (Diptera: Culicidae) eggs in Indiana. - Journal of Medical Entomology, 26(2): 122-129.

[22] Hijmans, R. J., Graham, C. H. (2006): The ability of climate envelope models to predict the effect of climate change on species distributions. - Global Change Biology 12(12): 2272-2281.

[23] Hochedez, P., Jaureguiberry, S., Debruyne, M., Bossi, P., Hausfater, P., Brucker, G., Bricaire, F., Caumes, E. (2006: Chikungunya infection in travelers. - Emerging Infectious Diseases 12(10): 1565.

[24] Ibáñez-Bernal, S., Briseno, B., Mutebi, J. P., Argot, E., Rodriguez, G., Martinez-Campos, C., Paz, R., de la Fuente-San Román, P., Tapia-Conyer, R., Flisser, A. (1997): First record in America of Aedes albopictus naturally infected with dengue virus during the 1995 outbreak at Reynosa, Mexio. - Medical and Veterinary Entomology, 11(4): 305-309.

[25] Jain, S. C. (Ed.). (2006). Emerging economies and the transformation of international business: Brazil, Russia, India and China (BRICs). Edward Elgar Publishing.

[26] Juliano, S. A., Lounibos, L. P. (2005): Ecology of invasive mosquitoes: effects on resident species and on human health. - Ecology Letters 8(5):558-74.

[27] Kalan, K., Kostanjšek, R., Merdić, E., Trilar, T. (2011): A survey of Aedes albopictus (Diptera: Culicidae) distribution in Slovenia in 2007 and 2010. - Natura Sloveniae: 12(2): 39-50.

[28] Klobučar, A., Merdic, E., Benic, N., Baklaic, Ž. L., Krčmar, S. A. (2006): First record of Aedes albopictus in Croatia. - Journal of the American Mosquito Control Association 22(1): 147-148.

[29] KNMI Climate Explorer. URL climexp.knmi.nl (accessed 22 Apr 2016).

[30] Knudsen, A. B., Romi, R., Majori, G. (1996): Occurrence and spread in Italy of Aedes albopictus, with implications for its introduction into other parts of Europe. - Journal of the American Mosquito Control Association, 12(2 Pt 1): 177-183.

[31] Medlock, J. M., Avenell, D., Barrass, I., Leach, S. (2006): Analysis of the potential for survival and seasonal activity of Aedes albopictus (Diptera: Culicidae) in the United Kingdom. - Journal of Vector Ecology, 31(2): 292-304.

[32] Merdić, E. (2011): Aedes albopictus: Invasive species in Croatia (past, present, surveillance and risk assessment). Simposium: Emerging vector-borne disease, the role of Aedes mosquitoes, Cervia 9-10, May 2011. [online publication] URL bib.irb.hr/prikazirad?lang=en\&rad=625208 [accessed 22 Apr 2016].

[33] Mitchell, C. J. (1995): Geographic spread of Aedes albopictus and potential for involvement in arbovirus cycles in the Mediterranean basin. - Journal of Vector Ecology 20(1): 44-58. 
[34] Moore, C. G., Mitchell, C. J. (1997): Aedes albopictus in the United States: ten-year presence and public health implications. - Emerging infectious diseases, 3(3): 329.

[35] Nawrocki, S. J., Hawley, W. A. (1987): Estimation of the northern limits of distribution of Aedes albopictus in North America. - Journal of the American Mosquito Control Association 3(2): 314-317.

[36] O'Meara, G. F., Evans, L. F. Jr., Gettman, A. D., Cuda, J. P. (1995): Spread of Aedes albopictus and decline of Ae. aegypti (Diptera: Culicidae) in Florida. - Journal of Medical Entomology 32(4): 554-562.

[37] OMSZ: http://www.met.hu/eghajlat/magyarorszag_eghajlata/ (accessed 0712 2014)

[38] Petrić, D., Pajović, I., Ignjatović-Ćupina, A., Zgomba, M. (2001): Aedes albopictus (Skuse, 1894), new mosquito species (Diptera: Culicidae) in entomofauna of Yugoslavia. - Biljni Lekar, 29(6): 547-548.

[39] Petric, D., Zgomba, M., Ignjatovic Cupina, A., Pajovic, I., Merdic, E., Boca, I., Landeka, N. (2006): In: Costas S editor. Invasion of the Stegomyia albopicta to a part of Europe. 15th European SOVE meeting. Program and abstract book, p 58. Prefecture of Serres, Center for Mosquito Abatement and CIVIC Protection of the Prefecture of Serres, Serres, Greece, 10-14 May 2006.

[40] Romi, R., Severini, F., Toma, L. (2006): Cold acclimation and overwintering of female Aedes albopictus in Roma. - Journal of the American Mosquito Control Association 22(1): 149-151.

[41] Sardelis, M. R., Turell, M. J., O'Guinn, M. L., Andre, R. G., Roberts, D. R. (2002): Vector competence of three North American strains of Aedes albopictus for West Nile virus. Journal of the American Mosquito Control Association 18(4): 284-289.

[42] Schaffner, F., Van Bortel, W., Coosemans, M. (2004): First record of Aedes (Stegomyia) albopictus in Belgium. - Journal of the American Mosquito Control Association 20(2): 201-203.

[43] Scholte, E. J., Schaffner, F. (2007): Waiting for the tiger: establishment and spread of the Aedes albopictus mosquito in Europe. In: Takken W. and Knols B.G.J. editors. Emerging pests and vector-borne diseases in Europe. Wageningen Academic Publishers, Wageningen, The Netherlands. p. 241-260.

[44] Šebesta, O., Rudolf, I., Betášová, L., Peško, J., Hubálek, Z. (2012): An invasive mosquito species Aedes albopictus found in the Czech Republic, 2012. - Eurosurveillance 17: 43.

[45] Sota, T., Mogi, M. (1992): Survival time and resistance to desiccation of diapause and non-diapause eggs of temperate Aedes (Stegomyia) mosquitoes. - Entomologia Experimentalis et Applicata, 63(2): 155-161.

[46] Thomas, S. M., Tjaden, N. B., van den Bos, S., Beierkuhnlein, C. (2014): Implementing cargo movement into climate based risk assessment of vector-borne diseases. International Journal of Environmental Research and Public Health 11(3): 3360-3374.

[47] Thomas, S. M., Obermayr, U., Fischer, D., Kreyling, J., Beierkuhnlein, C. (2012): Lowtemperature threshold for egg survival of a post-diapause and non-diapause European aedine strain, Aedes albopictus (Diptera: Culicidae). - Parasites \& vectors 5(1): 1.

[48] Thuiller, W., Araújo, M.B., Lavorel, S., (2004): Do we need land-cover data to model species distributions in Europe? - Journal of Biogeography 31(3): 353-361.

[49] Trájer, A. J., Bede-Fazekas, Á., Bobvos, J., Páldy, A. (2014): Seasonality and geographical occurrence of West Nile fever and distribution of Asian tiger mosquito. Időjárás-Quaternary Journal of the Hungarian Meteorological Service; 118(1): 19-40.

[50] Urbanelli, S., Bellini, R., Carrieri, M., Sallicandro, P., Celli, G. (2000): Population structure of Aedes albopictus (Skuse): the mosquito which is colonizing Mediterranean countries. - Heredity 84(3): 331-337.

[51] VBORNET (2015): Current known distribution of Aedes albopictus [January 2016]. URL http://VBORNET.europa.eu/en/healthtopics/vectors/vectormaps/Pages/VBORNET_maps.aspx [accessed 22 Apr 2016]. 
[52] Walther, G. R., Roques, A., Hulme, P. E., Sykes, M. T., Pyšek, P., Kühn, I., Zobel, M., Bacher, S., Botta-Dukát, Z., Bugmann, H., Czúcz, B., Dauber, J., Hickler, T., Jarošík, V., Kenis, M., Klotz, S., Minchin, D., Moora, M., Nentwig, W., Ott, J., Panov, V. E., Reineking, B., Robinet, C., Semenchenko, V., Solarz, W., Thuiller, W., Vilá, M., Vohland, K., Settele, J. (2009): Alien species in a warmer world: risks and opportunities. - Trends in ecology \& evolution 24(12): 686-693.

[53] Wong, P. S. J., Li, M. Z. I., Chong, C. S., Ng, L. C., Tan, C. H. (2013): Aedes (Stegomyia) albopictus (Skuse): a potential vector of Zika virus in Singapore. - PLoS Neglected Tropical Diseases 7: e2348. 